\title{
The relationship between leadership style and health worker motivation, job satisfaction and teamwork in Uganda
}

This article was published in the following Dove Press journal: Journal of Healthcare Leadership

\author{
Conrad Musinguzi' \\ Leticia Namale' \\ Elizeus Rutebemberwa ${ }^{2}$ \\ Aruna Dahal' \\ Patricia Nahirya-Ntege' \\ Adeodata Kekitiinwa' \\ 'Directorate of Health Systems \\ Strengthening, Baylor College of \\ Medicine Children's Foundation, \\ Kampala, Uganda; ${ }^{2}$ Department \\ of Health Policy, Planning and \\ Management, School of Public Health \\ Uganda, College of Health Sciences, \\ Makerere University, Kampala, Uganda
}

Correspondence: Conrad Musinguzi Baylor College of Medicine Children's Foundation, Block 5, Mulago Hospital, PO Box 72052, Clock Tower, Kampala, Uganda

Tel +2564l 71। 9100. ext I25

Email cmusinguzi@baylor-uganda.org
Background: Leadership is key to strengthening performance of Health Systems. Leadership styles are important organizational antecedents, especially in influencing employee's motivation, job satisfaction, and teamwork. There is limited research exploring this relationship among health workers in resource-limited settings such as Uganda. The aim of this study was to examine the relationship between transformational, transactional, and laissez-faire leadership styles and motivation, job satisfaction, and teamwork of health workers in Uganda.

Method: We conducted a cross-sectional study in 3 geographic regions of Uganda in November 2015, using self-administered questionnaires with 564 health workers from 228 health facilities. Data were collected on health workers' perception of leadership styles displayed by their facility leaders, their level of motivation, job satisfaction, and team work. Using Pearson correlation, relationships among variables were identified and associations of the components of leadership styles with motivation, job satisfaction, and teamwork was found using multivariable logistic regression.

Results: Health workers in Uganda preferred leaders who were transformational (62\%) compared with being transactional (42\%) or laissez-faire (14\%). Transformational leadership was positively correlated with motivation $(r=0.32)$, job satisfaction $(r=0.38)$, and team work $(r=0.48)$, while transactional leadership was positively correlated with job satisfaction $(r=0.21)$ and teamwork $(r=0.18)$. Motivation was positively associated with leaders who displayed idealized influence-behavior (odds ratio $[\mathrm{OR}]=3.7 ; 95 \% \mathrm{CI}, 1.33-10.48)$ and intellectual stimulation $(\mathrm{OR}=2.4 ; 95 \% \mathrm{CI}, 1.13-5.15)$ but negatively associated with management by exception $(\mathrm{OR}=0.4 ; 95 \% \mathrm{CI}, 0.19-0.82)$. Job satisfaction was positively associated with intellectual stimulation $(\mathrm{OR}=5.7 ; 95 \% \mathrm{CI}, 1.83-17.79)$. Teamwork was positively associated with idealized influence-behavior $(\mathrm{OR}=1.07-8.57)$, idealized influenceattributed $(\mathrm{OR}=3.9 ; 95 \% \mathrm{CI}, 1.24-12.36)$, and contingent reward $(\mathrm{OR}=5.6 ; 95 \% \mathrm{CI}, 1.87-17.01)$. Conclusion: Transformational styles had a positive impact on stimulating motivation, assuring job satisfaction, and consolidating teamwork among health workers compared with those who demonstrated transactional skills or laissez-faire styles.

Recommendation: Supporting transformational leadership skills development in health facility leaders could encourage health worker motivation, strengthen job satisfaction, and maintain cohesion among health workers for better service delivery.

Keywords: transformational leadership, transactional leadership, laissez-faire leadership, motivation, job satisfaction, teamwork

\section{Background}

Human resources for health are cornerstone in the delivery of health care but remain a crippling barrier in low-resource settings where human resources are in short supply 
or poorly managed. ${ }^{1}$ In Sub-Saharan Africa, this shortage has hindered sustainable health systems strengthening efforts and scale-up of interventions in the fight against human immunodeficiency virus/acquired immunodeficiency syndrome. ${ }^{1,2}$ In order to achieve the Sustainable Development Goals (SDGs), countries are called upon to focus on creating "real health care leaders" not just managers, to drive the agenda of SDGs. ${ }^{3}$ As a result, a cross-cutting pillar within health system strengthening approaches includes improving leadership to create a health workforce that is responsive, fair, and efficient given the available resources and circumstances. ${ }^{4}$

Since certain leadership styles have been associated with improved working environments and increased retention of excellent professionals, ${ }^{5}$ this study focuses on the 3 major leadership styles, which are transformational, transactional, and laissez-faire. Transformational leadership is characterized by leaders who exude a sense of admiration and respect amongst their followers (idealized influence attributed [IIa] and emphasize on a collective sense of mission (idealized influence behavior [IIb]), motivate, and inspire those around them (inspirational motivation [IM]), stimulate the follower's efforts (intellectual stimulation [IS]) and pay special attention to each individual (individualized consideration [IC]), while transactional leadership is characterized by a leader who only provides assistance in exchange for their efforts (contingent reward $[\mathrm{Cr}]$ ) and focuses attention on irregularities (management by exception active [MEa]), and finally, the laissez-faire leadership is characterized by a leader who fights fires (management by exception-passive [MEp]) and avoids involvement (laissez faire [Lf]). ${ }^{6}$ Since the early 1990s, transformational leadership style has been preferred over transactional leadership style ${ }^{7}$ because health care environment demands leaders who inspire others with the vision of what can be accomplished instead of promoting compliance through simply rewards and punishment. ${ }^{8}$

Low motivation and poor teamwork are still some of the greatest challenges in retention of health workers, especially in resource-limited settings. ${ }^{2}$ Health workers working in resource-limited settings commonly cite inadequate and outdated medical resources, ${ }^{9}$ limited career development opportunities, ${ }^{9,10}$ lack of promotion opportunities, ${ }^{11}$ and overwhelming work overload as a source of frustration and demotivation. ${ }^{11}$ This lack of motivation manifests in widespread absenteeism and a high attrition rate among health workers. $^{12-14}$

Addressing these challenges requires a strong leadership either acquired while on job or through some form of training. ${ }^{15}$ An example of such programs was a Leadership for Health World Health Organization Programme ${ }^{16}$ and the Caring Together Leadership Programme in Baylor College of Medicine Children's Foundation-Uganda. ${ }^{17}$ These programs focus on transforming leadership styles among health professionals who will then mentor frontline health workers to improve organizational dynamics, build teams, and foster effective communication.

Studies show that leadership styles exhibited by the health facility person in charge (in-charge) could determine the performance of his/her subordinate health workers, ${ }^{18}$ for example, charismatic leadership fosters good working relationships among health workers and builds resilient teams that can handle most of these challenges. ${ }^{8}$ On the other hand, overly controlling managers are likely to discourage individual initiative and creative thinking, while weak facility managers may fail to attend to staff requests or just avoid the challenges they face. ${ }^{18}$ Therefore, poor leadership styles result in the health workers becoming further dissatisfied, demotivated, and ultimately disengaged teams. ${ }^{19}$ However, the relationship between leadership style of the facility incharges and the motivation, job satisfaction, and teamwork among his/her subordinates has not been investigated in Uganda's health care context. As part of an ongoing longitudinal study to evaluate the impact of a leadership training program targeting frontline health workers on quality of health service delivery, this study was set up as a baseline with an objective of finding out if there is any relationship between leadership style of the facility in-charges and the level of motivation, job satisfaction, and teamwork among health workers working in rural parts of Uganda. Findings from the cross-sectional study should help us to understand and appreciate the theory of change the leadership program is striving to make.

The theoretical framework guiding this study was the Transformational Leadership Theory first developed by Burns $^{45}$ in 1978 and later expanded by Bass and Avolio ${ }^{20}$ to provide a useful model for effective leadership of health workers in modern health care settings.

\section{Methods}

\section{Research design}

This was a cross-sectional study. The data were collected from health workers using self-administered questionnaires that consisted of 4 sections: leadership style, job satisfaction, motivation, and teamwork. Since the unit of analysis was the facility level, we only collected demographic data about the health facility, which included the type of facility, district of origin, and region. 


\section{Study settings}

The study was conducted in 3 geographical regions of Uganda, namely; Rwenzori region that includes 7 districts of Kabarole, Kamwenge, Kyenjojo, Kasese, Bundibugyo and Ntoroko and Kyegegwa; Eastern region that includes 8 districts of Soroti, Amuria, Katakwi, Kaberamaido, Serere, Bukedea, Kumi, and Ngora; and West-Nile region that includes 8 districts of Arua, Adjumani, Nebbi, Koboko, Yumbe, Maracha, Moyo, and Zombo. This study was conducted among health workers working in the outpatient and maternity departments at 4 health facility levels of the Government health system, that is, health center (HC) IIs, HCIIIs, HCIVs, and general hospitals. We decided to pick health workers from the outpatient and maternity departments because these are the only departments found at each health facility level. ${ }^{21}$ As complexity of health service delivery increases exponentially as we move up the structure, services and their corresponding cadres found in one facility may not be found in another. For comparability purpose, we need to have a fairly similar profession of health workers.

Majority of the health workers who were approached were from HCIII. This was because sampling of health facilities was proportional to the distribution of health facilities by type in that district. Administratively, there were more HCIIIs in the districts compared with other health facility levels; therefore, by default, we had more health workers from HCIIIs.

\section{Sampling strategy and data collection}

Since this study was a baseline of a larger ongoing longitudinal evaluation study, sample size was determined using sample size calculation for clustered-randomization trials. ${ }^{22}$ This study had 90 health facilities in Rwenzori region (intervention), 90 health facilities in Eastern region (intervention), and 90 health facilities in the West-Nile region (control). In total, the sample size for this study was 270 health facilities.

Participating health facilities were selected from an inventory of all Baylor-Uganda supported/government-aided health facilities in the districts. A random sample of 90 health facilities proportional to the number and type of health facility were picked from each region. Using convenience sampling, we picked three health workers who were on duty that day ensuring that two of the three health health workers were picked from the maternity and out-patient department.

Data collection was carried out between November and December 2015 by the lead author and 12 research assistants for each region. Of the 270 health facilities, only 247 facilities were reached due to the logistical challenges and long distances. A total of 623 questionnaires were returned and
59 questionnaires were dropped due to missing data. Data from 233 out of 270 facilities were available for analysis; thus the overall facility response rate was $83.3 \%$. There was a fair distribution of facilities among the regions, that is, $37 \%, 34 \%$, and $28 \%$ from Eastern, Rwenzori, and West-Nile region, respectively. A total of $151(64.89 \%)$ of all facilities were HCIIIs, 55 (23.1\%) were HCIIs, 17 (7.30\%) were HCIVs, and 10 (4.3\%) were hospitals (Table 1).

\section{Measures}

\section{Leadership styles}

To measure leadership styles we adapted the Multifactor Leadership Questionnaire ${ }^{23}$ to which the health workers responded. The questionnaire measure dimensions of all the leadership styles; transformational, transactional and laissez faire. ${ }^{6}$ Participants were asked to indicate their perceptions about the leadership style of the person in charge of their respective health facilities by using a 4-point Likert scale ranging from "not at all (0)" to "frequently, if not always (3)." Cronbach's alpha $(\alpha)$ for Multifactor Leadership (41

Table I Health facility demographics

\begin{tabular}{|c|c|c|}
\hline Facility demographic & $\begin{array}{l}\text { Frequency } \\
(n=233)\end{array}$ & Percentage (\%) \\
\hline \multicolumn{3}{|l|}{ Region } \\
\hline Eastern & 88 & 37.77 \\
\hline Rwenzori & 81 & 34.76 \\
\hline West-Nile & 64 & 27.47 \\
\hline \multicolumn{3}{|l|}{ District } \\
\hline Adjumani & 15 & 6.44 \\
\hline Amuria & 14 & 6.01 \\
\hline Arua & 21 & 9.01 \\
\hline Bukedea & 8 & 3.43 \\
\hline Bundibugyo & 6 & 2.58 \\
\hline Kabarole & 25 & 10.73 \\
\hline Kaberamaido & 9 & 3.86 \\
\hline Kamwenge & 12 & 5.15 \\
\hline Kasese & 23 & 9.87 \\
\hline Katakwi & 16 & 6.87 \\
\hline Koboko & 7 & 3 \\
\hline Kumi & 9 & 3.86 \\
\hline Kyenjojo & 11 & 4.72 \\
\hline Maracha & 6 & 2.51 \\
\hline Ngora & 8 & 3.43 \\
\hline Ntoroko & 3 & 1.29 \\
\hline Serere & 13 & 5.58 \\
\hline Soroti & 12 & 5.15 \\
\hline Yumbe & 9 & 3.86 \\
\hline Zombo & 6 & 2.58 \\
\hline \multicolumn{3}{|l|}{ Health facility level } \\
\hline $\mathrm{HCll}$ & 55 & 23.61 \\
\hline $\mathrm{HCIII}$ & $|5|$ & 64.81 \\
\hline $\mathrm{HCIV}$ & 17 & 7.3 \\
\hline HOSP & 10 & 4.29 \\
\hline
\end{tabular}


items) was $\alpha=0.93$, which demonstrates very good reliability (an $\alpha$ of $>0.70$ ). This tool can be obtained from Mindgarden. ${ }^{23}$

\section{Motivation}

Motivation was measured using a motivation questionnaire. ${ }^{24}$ This instrument was composed of 23 items and 5 dimensions, that is, motivation due to supervision, pay, work done, demotivation due to burnout, and organization's administration. This tool required respondents to indicate social and psychological characteristics of their jobs using a 4-point Likert scale ranging from strongly disagree (1) to strongly agree (4). Cronbach's $\alpha$ for staff motivation was $\alpha=0.76$, which demonstrates good reliability (an $\alpha$ of $>0.70$ ). This tool has been attached in Figure S1.

\section{Job satisfaction}

In this study, health worker job satisfaction was captured using a job satisfaction questionnaire that was adapted from 2 job satisfaction questionnaires. ${ }^{25,26}$ This instrument was composed of 23 items that sought to capture the social and psychological characteristics of their job satisfaction using a 4-point Likert scale ranging from strongly disagree (1) to strongly agree (4). The Cronbach's $\alpha$ for item job satisfaction questionnaire was $\alpha=0.84$, which demonstrates a very good reliability (an $\alpha$ of $>0.70$ ). This tool has been attached in Figure S2.

\section{Teamwork}

Teamwork was measured as level of team climate, that is, shared perceptions of organizational policies, practices, and procedures. The original version Team Climate Inventory was a 61-item, 4-scale tool ${ }^{27}$ but for this study, we adapted a short form 12-item tool ${ }^{28}$ to measure teamwork among health workers. This instrument was composed of 14 items and 4 dimensions, that is, vision, participation safety, information sharing, and support for innovation. Health workers who participated were asked to indicate social and psychological characteristics of their jobs using a 4-point Likert scale ranging from Not at all (1) to Frequently or Always (4). The Cronbach's $\alpha$ for 14-item teamwork questionnaire was $\alpha=0.89$, which demonstrates a very good reliability (an $\alpha$ of $>0.70$ ). This tool has been attached in Figure S3.

The tools were all first pretested among health facilities in Central region, Wakiso district, during which we focused on the comprehensibility and relevance of the questions for all health workers and to localize some demographic and work-related questions to the Ugandan context. We later conducted a pilot test prior to data collection with the research assistants to ensure consistency of the interview techniques.

\section{Validity of questionnaires}

Convergent validity was assessed by performing item-scale correlations corrected for overlaps using Spearman's correlation coefficient (rho). It was expected that item scores would correlate higher with own hypothesized sub-category scales than other sub-category scales. For example, for using the Multifactor Leadership Questionnaire, sub-categories II, IS, IC, IM would correlate higher with transformational leadership style while $\mathrm{Cr}$, MEa would correlate higher with transactional leadership style and MEp, Lf would correlate higher with laissez-faire leadership style. The similar method was applied on motivation and team-climate questionnaires based on their sub-categories. Correlation values of 0.40 or above were considered satisfactory $(r \geq 0.81-1.0$ as excellent, $0.61-0.80$ very good, $0.41-0.60$ good, $0.21-0.40$ fair, and $0-0.20$ poor $)^{29}$

\section{Statistical analysis}

All forms that were returned were first checked for completeness by principal investigator and then entered in Microsoft Access 2010 by data entrants. Dataset was transferred to Stata software version 13.0 (STATA Corp., College Station, TX, USA) for analysis. All variables with 4-point Likert scales were collapsed into dichotomous variables to simplify analysis of the highly skewed responses on the 4-point Likert scale, and for better visualization of the results. ${ }^{31}$ Response 1-"Not at all" and 2-"Once in a while" were combined to form category "LESS," while 3-"Fairly often" and 4- "Frequent" formed "MORE."30

Some statements in the motivation questionnaire were negatively worded. We reversed responses to negative items so that higher scores indicate disagreement to these statements. We conducted 2 separate factor analyses to identify and confirm latent variables reported by the different questionnaires used. Exploratory factor analysis was done to identify latent variables reported by job satisfaction questionnaire and confirmatory factor analysis was done to confirm the latent factors reported. Five latent factors were identified from the job satisfaction questionnaire, while 11 latent factors of Mulitifactor Leadership Questionnaire, 4 of Team Climate Inventory, as well as 5 of the motivation questionnaire were confirmed.

Descriptive statistics including frequency and percentage were computed for all variables along with inferential statistics methods to include simple correlation to evaluate 
the correlations between leadership styles and job-related attributes (motivation, job satisfaction, and teamwork) and multiple logistic regression to assess the relationships between components of each leadership style as independent variables and job-related attributes as dependent ones.

\section{Ethical considerations}

This study was reviewed by the ethical review boards of Makerere University School of Public Health and Uganda National Council of Science and Technology and was granted institutional review board (IRB) approval, under research protocol No. 328 and National approval under registration Number SS 3952. According to the IRB protocol, an informed consent form was attached to the front page of the study data collection tools to explain and inform study participants about the study's aims and methods and to assure them that privacy and confidentiality of the data would be maintained. Following an explanation of the study, health workers who agreed to participate in the study completed the survey questionnaires anonymously and returned them to the research assistant at the end of the day.

\section{Results}

\section{Description of samples facilities and health worker job related perceived attributes}

Regarding the internal reliability of the 4 variables, Cronbach's $\alpha$ scores for each construct exceeded the level of 70 . According to Table 2, transformational leadership behavior was displayed more often in $77 \%$ (177/228) of health facilities, while transactional and laissez-faire leadership behaviors were displayed more often in $42 \%$ (97/228) and 14\% (32/228) of health facilities, respectively (Table 1). Health workers response was that $67 \%(153 / 228)$ were more motivated to work, $90.8 \%$ were satisfied with their jobs, and $86.8 \%$ work as teams. According to Table 2, there was moderate positive correlation between transformational leadership with team work $(r=0.48)$ and job satisfaction $(r=0.38)$ and slight correlation with motivation ( $r=0.32)$. Transactional leadership had a small positive correlation with job satisfaction $(r=0.21)$ and a very slight positive correlation with teamwork $(r=0.18)$.

\section{Correlation between leadership styles and motivation, job satisfaction, and teamwork}

Correlations as shown in Table 3 show that transformational leadership had a statistically significant positive relationship
Table 2 Descriptive characteristics of sampled health facilities

\begin{tabular}{ll}
\hline Major variables & Frequency (\%) $\mathbf{n = 2 2 8}$ \\
\hline Region & \\
Eastern & $88(37.8)$ \\
Rwenzori & $81(34.8)$ \\
West-Nile & $64(27.5)$ \\
Health facility level & \\
HC II & $55(23.6)$ \\
HC III & $151(64.8)$ \\
HC IV & $17(7.3)$ \\
Hospital & $10(2.9)$ \\
Transformational leadership & $51(22.4)$ \\
Low score & $17 \mid(77.6)$ \\
Higher score & \\
Transactional leadership & $131(57.5)$ \\
Low score & $97(42.5)$ \\
Higher score & \\
Laissez-faire leadership & $196(86.0)$ \\
Low score & $32(14.0)$ \\
Higher score & $75(32.9)$ \\
Motivation & $153(67.1)$ \\
Low score & $21(9.2)$ \\
Higher score & $207(90.8)$ \\
Job satisfaction & $30(13.2)$ \\
Low score & $197(86.8)$ \\
Higher score &
\end{tabular}

Abbreviation: $\mathrm{HC}$, Heath Center.

with motivation $(r=0.32)$, job satisfaction $(r=0.38)$, and teamwork $(r=0.48)$, while transactional leadership had a statistically significant positive relationship with job satisfaction $(r=0.21)$ and teamwork $(r=0.18)$. Though laissez-faire leadership was negatively correlated with motivation, job satisfaction, and team work, this was not statistically significant.

\section{Leadership components associated with motivation, job satisfaction, and teamwork}

Leadership components that were positively associated with health worker motivation were II behavior and intellectual stimulation, that is, the odds of high motivation increase almost 4-fold with each unit increase in facilities whose leaders have more of idealized influence behavior ( $\mathrm{OR}=3.7 ; 95 \%$ CI, 1.33-10.48) and 2-fold in those with more of IS behavior $(\mathrm{OR}=2.4 ; 95 \% \mathrm{CI}, 1.13-5.15)$ but decreased almost 3-fold in those with more of management by exception behavior $(\mathrm{OR}=0.4 ; 95 \% \mathrm{CI}, 0.22-0.85)$. Job satisfaction increased almost 6-fold with each unit increase among facilities whose leaders had more of IS behavior ( $\mathrm{OR}=5.7 ; 95 \% \mathrm{CI}$, 1.83-17.79). The leadership components that were positively 
associated with teamwork among health workers were II behavior and $\mathrm{Cr}$, that is, $\mathrm{OR}=3.9 ; 95 \% \mathrm{CI}, 1.24-12.36$ and 5.6; 95\% CI, 1.87-17.01, respectively, as shown in Table 4.

\section{Discussion}

Much as extensive research has been made on the relationship between leadership styles and job-related behaviors in health care, ${ }^{31-33}$ there is limited research on exploring this relationship among health workers in resource-limited settings like Uganda. Results from this study indicate that health workers in Uganda preferred leaders who were transformational compared with being transactional or laissez-faire. Staff motivation, job satisfaction, and teamwork were positively correlated with transformational leadership whereas only staff job satisfaction and teamwork were positively correlated with transactional leadership. Motivated staff was positively associated with leaders who exhibited II (behavior and attributed) but negatively associated with those who exhibited management by exception. Job satisfaction was positively associated with only IS. Teamwork was positively associated with II (behavior and attributed) and $\mathrm{Cr}$.

The study was able to conclude that the more transformational the health facility manager was, the more motivated, satisfied, and team-spirited the health worker subordinates will be compared with those whose health facility managers were transactional or laissez-faire. This finding was consistent with a study in Jimma University Hospital, which found that

Table 3 Correlations between leadership styles and workerrelated behaviors among health workers in Uganda

\begin{tabular}{llll}
\hline $\begin{array}{l}\text { Work- } \\
\text { related } \\
\text { behavior }\end{array}$ & Transformational & Transactional & Laissez-faire \\
\hline Motivation & $0.32^{*}$ & 0.05 & -0.09 \\
Teamwork & $0.48^{*}$ & $0.18^{*}$ & -0.03 \\
Job satisfaction & $0.38^{*}$ & $0.21^{*}$ & -0.05 \\
\hline
\end{tabular}

Notes: *Denotes statistically significant values whose $P$-value $\leq 0.05$ staff nurses preferred leaders with transformational rather than transactional styles. ${ }^{8}$ This is because transformational leaders possess components of charisma and IM that can bring out the best in a worker.

Facilities whose leaders adopt transformational leadership have the ability to motivate their staff compared with those whose leaders adopted transactional leadership. Specifically, facility leaders who were seen to exhibit management by exception behavior were less likely to motivate their subordinates. This finding was similar to a study, which found that from the employee's perspective, transformational leadership is positively, significantly correlated with employee autonomous motivation ${ }^{34}$ and management by exception was significantly negatively correlated with motivation. ${ }^{34}$ Therefore, the more subordinates perceived their leaders to be transformational, the more likely they were motivated and when subordinates perceived their leaders to use passive management-by-exception, subordinates tended to lose their enthusiasm.

In Uganda today, motivating workers who are poorly paid and work in difficult circumstances is still challenging. This forces leaders to maintain the "status quo," that is, back away from problems, ${ }^{35}$ which will definitely demotivate staff. In 2007, a retention study done in Uganda to assess satisfaction and intent to stay among current health workers found that lack of supplies or equipment was viewed as being beyond anyone's means of control but when coupled with poor management, which is usually the root cause, health workers said it was especially frustrating to them. ${ }^{36}$

Health workers whose supervisors' behaviour was more transformational specifically IS, were more likely to be satisfied with their jobs. These findings were consistent with a study in Ethiopia, ${ }^{8}$ which found that, of all transformational leadership dimensions, the beta coefficients of IS had the strongest correlation with both intrinsic and extrinsic job satisfaction. This could be because leaders who display IS assist followers to develop new ideas, and motivate them to

Table 4 Logistic regression of components of each leadership style with motivation, job satisfaction, and teamwork

\begin{tabular}{|c|c|c|c|c|c|c|}
\hline \multirow[t]{2}{*}{ Leadership styles } & \multicolumn{2}{|l|}{ Motivation } & \multicolumn{2}{|l|}{ Job satisfaction } & \multicolumn{2}{|l|}{ Teamwork } \\
\hline & $\begin{array}{l}\text { Unadjusted } \\
\text { OR }(95 \% \mathrm{Cl})\end{array}$ & $\begin{array}{l}\text { Adjusted } \\
\text { OR }(95 \% \mathrm{Cl})\end{array}$ & $\begin{array}{l}\text { Unadjusted } \\
\text { OR }(95 \% \mathrm{Cl})\end{array}$ & $\begin{array}{l}\text { Adjusted } \\
\text { OR }(95 \% \mathrm{Cl})\end{array}$ & $\begin{array}{l}\text { Unadjusted } \\
\text { OR }(95 \% \mathrm{Cl})\end{array}$ & $\begin{array}{l}\text { Adjusted } \\
\text { OR }(95 \% \mathrm{Cl})\end{array}$ \\
\hline Idealized influence attributed ${ }^{\alpha}$ & & & & & $9.8(4.14-23.01)$ & $3.0(1.07-8.57)$ \\
\hline Idealized influence behavior ${ }^{\alpha}$ & $7.1(2.82-17.75)$ & $3.7(1.33-10.48)$ & & & $18.7(7.18-48.72)$ & $3.9(1.24-12.36)$ \\
\hline Intellectual stimulation ${ }^{\alpha}$ & $4.0(2.06-7.62)$ & $2.4(1.13-5.15)$ & $12.2(4.45-33.87)$ & $5.7(1.83-17.79)$ & & \\
\hline Contingent reward ${ }^{\alpha}$ & & & & & $16.6(6.73-40.93)$ & $5.6(I .87-\mid 7.0 I)$ \\
\hline Management by exception ${ }^{\alpha}$ & $0.4(0.22-0.85)$ & $0.4(0.19-0.82)$ & & & & \\
\hline
\end{tabular}

Notes: The model was controlled for health facility level ( $\mathrm{HCll}, \mathrm{HClll}, \mathrm{HCIV}$ and hospital) and region (Eastern, Rwenzori, and West-Nile). ${ }^{\alpha} \mathrm{Two}$ groups: $0=$ less often vs. I=more often; Group I is reported. 
take alternative routes to problem solving..$^{34}$ Non-association with other components could be related to the fact that in countries, for example, Uganda, with limited health workforce, many health care providers take on significant health leadership roles, despite minimal formal training in leadership skills ${ }^{37}$ and therefore will be unable to guarantee job satisfaction due to limited skills to provide performancebased appraisals and feedback to subordinates. ${ }^{38}$

Team work among health workers was more likely in facilities where the leader was transformational and transactional as well. This finding is consistent with a study in the Netherlands that realized that much as the teams flourished under a leader who was more charismatic and approachable compared with one who was mostly displaying transactional leadership traits, a mixed leadership is regarded as the most effective. ${ }^{39,40}$ For leadership to be most effective, one should be able and willing to adapt according to the situation at hand. Working environment in most of the health facilities in Uganda is considered to be dynamic and constantly changing, ${ }^{37}$ therefore the leadership style should be mixed and the leader should have the ability to adapt to a style fitting to the occurring situation. ${ }^{39,41}$

The study also found that $\mathrm{Cr}$ was the strongest predictor for team work among health workers. This study was consistent with a report of a rewards project in Uganda which, according to its project manager, had registered improved performance, targets achievement, and an enhanced balance between functions and roles. ${ }^{42}$ This could be because health workers may have been "awakened" by performance bonuses, and improved working environments and greater cohesion among staff. ${ }^{43}$

\section{Strengths and limitation of this study}

The greatest strength of this study was the comprehensive overview of the job related behaviors affecting health workers in Uganda. We used a large sample size (564 health workers, which was collapsed to 228 health facilities) and a high response rate $(83.3 \%)$, which indicates that effect of response bias was likely minimal.

Findings should be interpreted with caution in view of the following limitation: convenience sampling of health workers who reported that day was used. This creates some form of selection bias because respondents who agreed to participate may be friendly to in-charge who selected them or if the in-charge was not involved, are more inclined to respond positively due to social desirability bias. Second, in bigger facilities (Health Center IVs and hospitals) with many health workers, three health workers may not be representative of all the health workers in the health facility. Third, considering the complexity of the socially determined constructs (job satisfaction, motivation, and teamwork), the use of a single item to measure it might be disputable. There may be other moderating factors, such as professional backgrounds, family demands, work condition and climate, patient load, mandatory overtime, shifts, and unit type, income, and age. Fourth, because we used a cross-sectional design, we only took measures once and relied on self-administered questionnaires that may lead to bias, so no causal relationship can be inferred. Finally, validity of these questionnaires was not exhaustively checked in this paper as we could only manage to check for convergent validity.

\section{Conclusion}

Findings from this study show that even in resourceconstrained settings, transformational leadership style is exhibited much more than transactional or laissez-faire leadership styles. The study further found that leaders who demonstrated transformational skills had a positive impact on stimulating motivation, assuring job satisfaction, and consolidating teamwork among health workers compared with those who demonstrated transactional skills. Leaders who demonstrated laissez-faire characteristics had a negative effect on consolidating teamwork among health workers. Therefore, strengthening transformational skills will not only improve providers' job satisfaction and staff retention, but will also ensure efficiency in health care delivery in Uganda.

\section{Implication of the study}

This study builds on existing leadership literature by providing further evidence for the relationship between leadership styles on follower's behavior. ${ }^{44}$ Therefore, the findings of this study contribute to the existing literature on the effect of transformation leadership and transactional leadership on health worker's motivation, job satisfaction, and teamwork in Uganda. Further studies could evaluate other mediating factors that bring about this effect, assess the benefits, challenges, and financial implications of developing innovative leadership styles in resource-limited health settings, especially in regions facing a high shortage of health workers Results from this study can be used to better inform policy makers who want to address issues of staff retention. These results indicate that any health worker who can emulate these leadership skills, can enhance fellow staff motivation, job satisfaction, and encourage teamwork. 


\section{Availability of data and materials}

All the data supporting the presented findings is contained within the manuscript. The dataset that was used to write this manuscript has been submitted alongside other supplementary documents.

\section{Acknowledgments}

The authors extend their thanks to all the health workers in these regions who participated in this study, the officials in the District Health Office for the permission to carry out the study in their jurisdiction, and guidance and support during data collection, and the facility in-charges from each health facility for warm welcome during data collection. We deeply appreciate the contribution of all the research assistants that participated in data collection and the regional staff of Baylor College of Medicine Children's Foundation staff who were instrumental in linking us to the health facilities. Special thanks go to Caring Together leadership project team; Michael Musiime, Wilson Eceditai, Benjamin Echeku and Innocent Erone for the support during study conception, data collection and data entry.

This study received funds from Janssen Pharmaceutical and Pepal-UK. The funding sources were in no way involved in the collection, analysis or interpretation of the data, or writing the paper.

\section{Author contributions}

$\mathrm{CM}$ and $\mathrm{AD}$ conceived the study and worked with ER and $\mathrm{LN}$ to design the questionnaires for data collection. $\mathrm{CM}$ and ER performed the statistical analysis and drafted the methods and results sections of the manuscript. $\mathrm{LN}$ and $\mathrm{AD}$ drafted the other sections of the manuscript. PNN and AK provided a critical review of the manuscript. All authors contributed toward data analysis, drafting and critically revising the paper and agree to be accountable for all aspects of the work.

\section{Disclosure}

The authors report no conflicts of interest in this work.

\section{References}

1. World Bank. World Development Report 2004: Making Services Work for Poor People. World Bank and Oxford University Press. Washington, DC: 2003. 2004.

2. Marjolein D, Jan WH. Improving Health Worker Performance: In Search of Promising Practices. Evidence and Information for Policy, Department of Human Resources for Health Geneva, September 2006: KIT - Royal Tropical Institute The Netherlands; 2006.

3. Obinna OO, Simon DT-R. Before Sustainable Development Goals (SDG): why Nigeria failed to achieve the Millennium Development Goals (MDGs). Pan Afr Med J. 2016;24(156).
4. Szekeres G, Coates TJ, Ehrhardt AA. Leadership development and HIV/ AIDS. AIDS (London, England). 2008;22(Suppl 2):S19-S26.

5. Wong CA, Cummings GG, Ducharme L. The relationship between nursing leadership and patient outcomes: a systematic review update. J Nurs Manag. 2013;21(5):709-724.

6. Eagly AH, Johannesen-Schmidt MC, van Engen ML. Transformational, transactional, and laissez-faire leadership styles: a meta-analysis comparing women and men. Psychological Bulletin 2003;129(4):569-591.

7. Ramey JW. The Relationship between Leadership Styles of Nurse Managers and Staff Nurse Job Satisfaction in Hospital Settings. [Masters thesis], Huntington, West Virginia: Marshall University College of Nursing and Health Professions. 2002.

8. Negussie N, Demissie A. Relationship between leadership styles of nurse managers and nurses' job satisfaction in Jimma University Specialized Hospital. Ethiop J Health Sci. 2013;23(1):49-58.

9. Kotzee TJ, Couper. ID. What interventions do South African qualified doctors think will retain them in rural hospitals of the Limpopo province of South Africa. Rural Remote Health. 2006;(3)6:581.

10. Willis-Shattuck, Mischa PB, Steve T, Laura W, Duane B, Prudence D. Motivation and retention of health workers in developing countries: a systematic review. BMC Health Serv Res. 2008;(1)8:247.

11. Manongi RN, Marchant T, Bybjerg C. Improving motivation among primary health care workers in Tanzania: a health worker perspective. Hum Resour Health. 2006;4:6.

12. Driessen J, Settle D, Potenziani D, Tulenko K, Kabocho T, Wadembere I. Understanding and valuing the broader health system benefits of Uganda's national Human Resources for Health Information System investment. Hum Resour Health. 2015;13(1):1.

13. Spero JC, McQuide PA, Matte R. Tracking and monitoring the health workforce: a new human resources information system (HRIS) in Uganda. Hum Resour Health. 2011;9:6

14. Lutwama GW, Roos JH, Dolamo BL. A descriptive study on health workforce performance after decentralisation of health services in Uganda. Hum Resour Health. 2012;10:41.

15. Ammer S. Despite impending and relatively growth: factors influencing the expansion of nurses involvement in health profession. J Riyadh Trading. 2001;4176(74):46.

16. World Health Organization. [webpage on the Internet]. Second round of Leadership for Health programme, 15 November 2015-30 January 2016. Available from http://www.emro.who.int/about-who/regionaldirector/second-round-of-leadership-for-health-lfh-programme.html. Accessed March 22, 2018.

17. Baylor College of Medicine Children's Foundation, Uganda. [webpage on the Internet]. Caring Together. Availalbe from https://www.bayloruganda.org/health-systems-strengthening/caring-together/. Accessed April 9, 2018

18. Asiri SA, Rohrer WW, Al-Surimi K, Da'ar OO, Ahmed A. The association of leadership styles and empowerment with nurses' organizational commitment in an acute health care setting: a cross-sectional study. BMC Nurs. 2016;15:38.

19. Laschinger H, Finegan J, Shamian J, Almost J. Testing Karasek's DemandsControl Model in restructured healthcare settings: effects of job strain on staff nurses' quality of work life. J Nurs Adm. 2001;3(5):233-243.

20. Bass BM, Avolio BJ. Developing transformational leadership: 1992 and beyond. J Eur Industr Train. 1990;14(5).

21. Richard MK. Uganda's healthcare system explained. The Guardian Newpaper. 2009. Available from https://www.theguardian.com/katine/2009/ apr/01/uganda-healthcare-system-explained. Accessed May 11, 2017.

22. Hayes R, Bennett S. Simple sample size calculation for clusterrandomized trials. Int J Epidemiol. 1999;28(2):319-326.

23. Bruce A, Bass B. Multifactor Leadership Questionnaire Includes Actual form and Ought form and Scoring Guide. Published by Mind Garden, Inc. Available from: http://www.mindgarden.com/16-multifactorleadership-questionnaire. Accessed March 22, 2018.

24. Mbindyo PM, Blaauw D, Gilson L, English M. Developing a tool to measure health worker motivation in district hospitals in Kenya. Hum Resour Health. 2009;7(1):40. 
25. Bodur S. Job satisfaction of health care staff employed at health centres in Turkey. Occup Med. 2002;52(6):353-355.

26. Weiss DJ, Dawis RV, England GW. Manual for the Minnesota satisfaction questionnaire. Minnesota Stud Voc Rehabil. 1967. Available from www.fep.up.pt/investigacao/workingpapers/wp471.pdf.

27. Anderson NR, West MA. Measuring climate for work group innovation: development and validation of the team climate inventory. $J$ Organ Behav. 1998;189(3):235-258.

28. Kivimaki M, Elovainio M. A short version of the Team Climate Inventory: development and psychometric properties. JOccup Organ Psychol. 1999;72(2):241-246.

29. Nunnally JC, Bernstein IH. Psychometric Theory. 3rd ed. New York, NY: McGraw-Hill; 1994.

30. ResearchGate. [webpage on the Internet]. Panezai S. Q \& A Thread: Can it be justified to change the "four-point Likert scale outcome variable" to a "binary variable" through re-coding of the dependent variable? [Msg2, Msg 3]. Available from www.researchgate.net/post/ Can_it_be_justified_to_change_the_four-point_Likert_scale_outcome_ variable_to_a_binary_variable_through_re-coding_of_the_dependent_variable. Accessed April 21, 2017.

31. Suliman WA. Leadership styles of nurse managers in a multinational environment. Nurs Adm Q. 2009;33(4):301-309.

32. Wylie DA, Gallagher HL. Transformational leadership behaviors in allied health professions. J Allied Health. 2009;38(2):65-73.

33. McNaron ME. Using transformational learning principles to change behavior in the OR. AORN J. 2009;89(5):851-860.

34. Goodridge D. Relationships between Transformational and Transactional Leadership with the Motivation of Subordinates [master thesis]. Concordia University; 2006.

35. O’Neil M, La Rue Seims M, Cheburet S, et al. 10. Leadership and management to empower the health workforce. In Transforming the Global Health Workforce. New York: New York University, College of Nursing. 2013:225.
36. Ministry of Health, The Republic of Uganda. Uganda Health Workforce Study: Satisfaction and Intent to Stay Among Current Health Workers. 2006. Available from https://capacityproject.org/images/stories/files/ exec_sum_retention_study_final.pdf. Accessed March 22, 2018.

37. Nakanjako D, Namagala E, Semeere A, et al. Global health leadership training in resource-limited settings: a collaborative approach by academic institutions and local health care programs in Uganda. Hum Resour Health. 2015;13(1):87.

38. Mathauer I, Imhoff I. Health worker motivation in Africa: the role of non-financial incentives and human resource management tools. Hum Resour Health. 2006;4(1):24.

39. Jansen R. Transactional \& Transformational Leadership Style, Motivation and the Effect on Team Performance \& Team Creativity (Stripped/ Edited Version) [Masters thesis]. University of Amsterdam; 2013.

40. Bass BM. Leadership and Performance Beyond Expectations. New York, NY: The Free Press; 1985.

41. House RJ. Path-goal theory of leadership: lessons, legacy, and a reformulated theory. Lead Q. 1996;7(3):323-352.

42. PeopleinAid. TPO Uganda's Staff Reward Programme Improves Performance and Builds Relationships; 2013. Available from: http://www. chsalliance.org/files/files/Resources/Case-Studies/CaseStudy-TPOUgandaStaffRewardandMotivationProgrammeFINAL.pdf. Accessed January 20, 2017.

43. Bhatnagar A. Determinants of motivation and job satisfaction among primary health workers: case studies from Nigeria and India $[\mathrm{PhD}$ Thesis]. Johns Hopkins Bloomberg School of Public Health, Baltimore, USA; 2014.

44. Bass BM, Avolio BJ. Improving Organizational Effectiveness through Transformational Leadership. Thousand Oaks, CA: Sage; 1994.

45. Burns JMG. Leadership. Harper \& Row; 1978. 


\section{Supplementary material}

Instructions

1. This questionnaire is to be filled by health workers found at the health facility during the time of visit.

2. All health workers are eligible to participate but should be persons who are in contact with patients at the health facility. Examples are nurses, clinicians, laboratory staff, etc.

\section{Background information}

$\begin{array}{ll}\text { HF_ID } & \text { Health facility code } \\ \text { HF_NAM } & \text { Health facility Name } \\ \text { HF_LEV } & \text { Health facility level } \\ \text { HF_REG } & \text { Region } \\ \text { HF_DIS } & \text { District } \\ \text { HF_NOI } & \text { Code of interviewer } \\ \text { HF_HW_01 } & \text { Date of the visit }\end{array}$

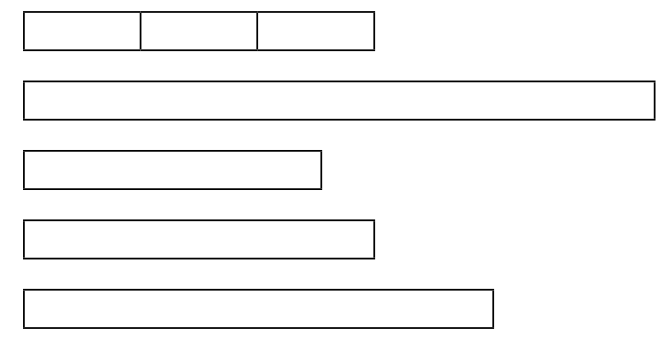

Instruction: We would like to assess your level of motivation to work in this health facility.

Basing on your current situation, Use the options below to describe/rate the level of agreement with each statement by placing a tick or circle in the boxes on the right.

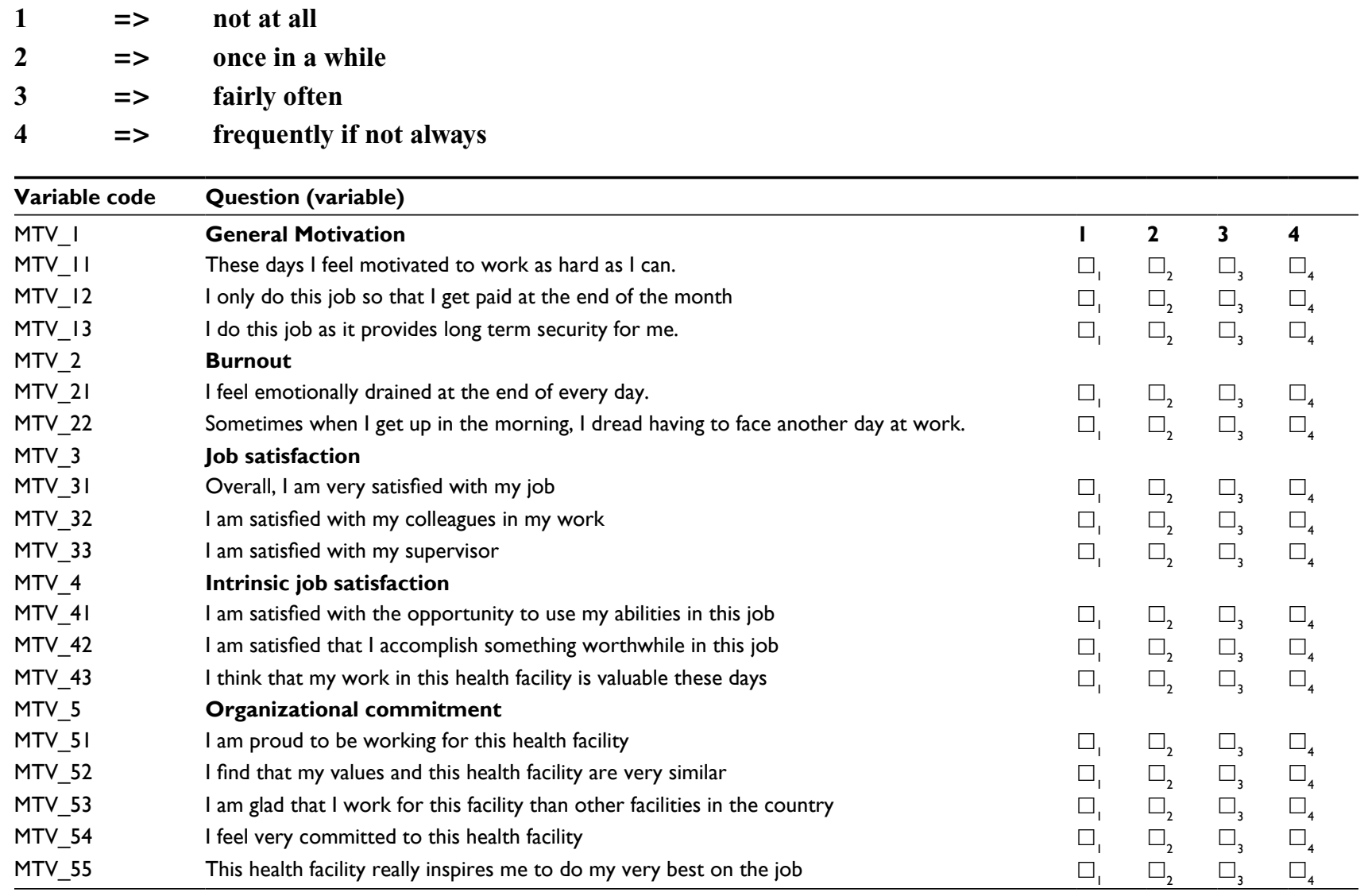




\begin{tabular}{|c|c|c|c|c|c|}
\hline Variable code & Question (variable) & & & & \\
\hline$\overline{M T V \_6}$ & Conscientiousness & & & & \\
\hline MTV_6I & I am always relied on by my colleagues at work & $\square_{1}$ & $\square_{2}$ & $\square_{3}$ & $\square_{4}$ \\
\hline MTV_62 & I always complete my tasks efficiently and correctly & $\square_{1}$ & $\square_{2}^{2}$ & $\square_{3}$ & $\square_{4}^{4}$ \\
\hline MTV_63 & I am a hard worker & $\square_{1}$ & $\square_{2}$ & $\square_{3}$ & $\square_{4}$ \\
\hline MTV_64 & I do things that need doing without being asked or told & $\square_{1}$ & $\square_{2}$ & $\square_{3}$ & $\square_{4}$ \\
\hline MTV_7 & Timelines and attendance & & & & \\
\hline MTV_7I & I am punctual about coming to work & $\square_{1}$ & $\square_{2}$ & $\square_{3}$ & $\square_{4}$ \\
\hline MTV_72 & I am always present at work & $\square_{1}$ & $\square_{2}$ & $\square_{3}$ & $\square_{4}$ \\
\hline MTV_73 & It is not a problem if I sometimes come late for work & $\square_{1}$ & $\square_{2}$ & $\square_{3}$ & $\square_{4}$ \\
\hline
\end{tabular}

Figure SI Motivation questionnaire for health workers.

\section{Instruction: We would like to assess the level of teamwork in this facility}

Basing on your current situation, please rate the level of agreement with each statement by placing a tick or circle in the boxes according to the instruction below;

$1 \quad \Rightarrow \quad$ not at all

$2 \quad \Rightarrow \quad$ once in a while

$3 \Rightarrow$ fairly often

$4 \quad \Rightarrow \quad$ frequently if not always

\begin{tabular}{|c|c|c|c|c|c|}
\hline & Statements & $\begin{array}{l}\text { Not } \\
\text { at all }\end{array}$ & $\begin{array}{l}\text { Once in } \\
\text { a while }\end{array}$ & $\begin{array}{l}\text { Fairly } \\
\text { often }\end{array}$ & $\begin{array}{l}\text { Frequently if } \\
\text { not always }\end{array}$ \\
\hline TWK_I & $\begin{array}{l}\text { To what extent do you think your team's objectives are clearly understood by other } \\
\text { members of the team? }\end{array}$ & $\square_{1}$ & $\square_{2}$ & $\square_{3}$ & $\square_{4}$ \\
\hline TWK_2 & To what extent do you think your team's objectives have actually been achieved? & $\square_{1}$ & $\square_{2}$ & $\square_{3}$ & $\square_{4}$ \\
\hline TWK_3 & How worthwhile do you think these objectives are suited to the organization? & $\square_{1}$ & $\square_{2}$ & $\square_{3}$ & $\square_{4}$ \\
\hline TWK_4 & At this facility/department, we have a "We are in it together" attitude & $\square_{1}$ & $\square_{2}$ & $\square_{3}$ & $\square_{4}$ \\
\hline TWK_5 & Staff keep each other informed about work-related issues in the team. & $\square_{1}$ & $\square_{2}$ & $\square_{3}$ & $\square_{4}$ \\
\hline TWK_6 & Staff feel understood and accepted by each other. & $\square_{1}$ & $\square_{2}$ & $\square_{3}$ & $\square_{4}$ \\
\hline TWK_7 & There are real attempts to share information throughout the team & $\square_{1}$ & $\square_{2}$ & $\square_{3}$ & $\square_{4}$ \\
\hline TWK_8 & Are team members prepared to question the basis of what the team is doing? & $\square_{1}$ & $\square_{2}$ & $\square_{3}$ & $\square_{4}$ \\
\hline TWK_9 & $\begin{array}{l}\text { As a team, do you critically appraise your potential weaknesses in order to achieve the } \\
\text { best possible outcomes? }\end{array}$ & $\square_{1}$ & $\square_{2}$ & $\square_{3}$ & $\square_{4}$ \\
\hline TWK_10 & $\begin{array}{l}\text { Do members of the team build on each other's ideas in order to achieve the best } \\
\text { possible outcome? }\end{array}$ & $\square_{1}$ & $\square_{2}$ & $\square_{3}$ & $\square_{4}$ \\
\hline TWK_II & People in this team are always searching for fresh, new ways of looking at problems. & $\square_{1}$ & $\square_{2}$ & $\square_{3}$ & $\square_{4}$ \\
\hline TWK_12 & In this team we take the time needed to develop new ideas. & $\square_{1}$ & $\square_{2}$ & $\square_{3}$ & $\square_{4}$ \\
\hline TWK_13 & Staff in the team cooperate in order to help develop and apply new ideas. & $\square_{1}$ & $\square_{2}$ & $\square_{3}$ & $\square_{4}$ \\
\hline
\end{tabular}

Figure S2 Teamwork questionnaire for health workers.

\section{We would like to assess the level of Job Satisfaction you have in your job at this health facility}

Basing on your current situation, please rate the level of agreement with each statement by placing a tick or circle in the boxes according to the instruction below;

$\begin{array}{lll}1 & \Rightarrow & \text { not at all } \\ 2 & \Rightarrow & \text { once in a while } \\ 3 & \Rightarrow & \text { fairly often } \\ 4 & \Rightarrow & \text { frequently if not always }\end{array}$


Considering everything, I am satisfied with my job

When I come to work, I know what is expected of me

I have good friends at work

I am actively involved in helping to make this a great health care facility

The job is a good match for my skills and experience

I consider myself a part of this community

I would encourage my friends and family to seek care here

My supervisor is available when I need support

I feel respected at work because my opinion seems to matter

I have been given the training needed to succeed in my position

I am fairly evaluated on my work

My immediate supervisor cares about me as a person

The managers in this health facility are committed and competent

I have the flexibility to balance the demands of my workplace and my personal life

The organization takes specific measures to protect me against infection

I receive recognition for doing good work

In the past six months, someone has talked to me to encourage my development

Overall, the morale level at my department or section is good

This is a fun place to work; The work I am doing is stimulating

I have been abused (physically, emotionally, verbally) by a supervisor

I have been abused (physically, emotionally, verbally) by patients/their friends/family members

I have been abused (physically, emotionally, verbally) while traveling to/from work

I have been abused (physically, emotionally, verbally) by my Colleagues.

$\begin{array}{llll}\square_{1} & \square_{2} & \square_{3} & \square_{4} \\ \square_{1} & \square_{2} & \square_{3} & \square_{4} \\ \square_{1} & \square_{2} & \square_{3} & \square_{4} \\ \square_{1} & \square_{2} & \square_{3} & \square_{4} \\ \square_{1} & \square_{2} & \square_{3} & \square_{4} \\ \square_{1} & \square_{2} & \square_{3} & \square_{4} \\ \square_{1} & \square_{2} & \square_{3} & \square_{4} \\ \square_{1} & \square_{2} & \square_{3} & \square_{4} \\ \square_{1} & \square_{2} & \square_{3} & \square_{4} \\ \square_{1} & \square_{2} & \square_{3} & \square_{4} \\ \square_{1} & \square_{2} & \square_{3} & \square_{4} \\ \square_{1} & \square_{2} & \square_{3} & \square_{4} \\ \square_{1} & \square_{2} & \square_{3} & \square_{4} \\ \square_{1} & \square_{2} & \square_{3} & \square_{4} \\ \square_{1} & \square_{2} & \square_{3} & \square_{4} \\ \square_{1} & \square_{2} & \square_{3} & \square_{4} \\ \square_{1} & \square_{2} & \square_{3} & \square_{4} \\ \square_{1} & \square_{2} & \square_{3} & \square_{4} \\ \square_{1} & \square_{2} & \square_{3} & \square_{4} \\ \square_{1} & \square_{2} & \square_{3} & \square_{4} \\ \square_{1} & \square_{2} & \square_{3} & \square_{4} \\ \square_{1} & \square_{2} & \square_{3} & \square_{4} \\ \square_{1} & \square_{2} & \square_{3} & \square_{4} \\ & & & \end{array}$

Figure S3 Job satisfaction questionnaire.

\section{Publish your work in this journal}

The Journal of Healthcare Leadership is an international, peer-reviewed, open access journal focusing on leadership for the health profession. The journal is committed to the rapid publication of research focusing on but not limited to:

Healthcare policy and law; Theoretical and practical aspects of healthcare delivery; Interactions between healthcare and society and evidence-based practices;
Interdisciplinary decision-making; Philosophical and ethical issues; Hazard management; Research and opinion for health leadership; Leadership assessment. The manuscript management system is completely online and includes a very quick and fair peer-review system. Visit http://www.dovepress.com/ testimonials.php to read real quotes from published authors. 